\section{¿CLONAR HUMANOS? LÍMITES DE LA EUGENESIA}

\author{
Francisco J. Ayala \\ University of California \\ ORCID iD: https://orcid.org/0000-0003-1026-5398 \\ fjayala@uci.edu
}

Cómo citar este artículo/Citation: Ayala, F. J. (2019). ¿Clonar humanos? Límites de la eugenesia. Arbor, 195 (792): a502. https://doi.org/10.3989/arbor.2019.792n2003

Recibido: 30 septiembre 2015. Aceptado: 28 abril 2016.

RESUMEN: La humanidad no solo ha evolucionado, sino que continúa evolucionando. ¿Hacia dónde va la evolución humana? La evolución biológica está dirigida por la selección natural, que no es un proceso benevolente que guíe a las especies hacia un éxito seguro. El resultado final puede ser la extinción. Los avances en genética, biología molecular y biomedicina han hecho posible manipular, rápida y efectivamente, la constitución genética de la humanidad. La terapia genética puede ser somática (corregir un defecto genético en los órganos o tejidos afectados), o germinal (evitando su transmisión a los descendientes). No hay intervenciones de terapia germinal que estén siendo consideradas actualmente por científicos, médicos o compañías farmacéuticas. La clonación de humanos puede también referirse a clonación terapéutica o de individuos. Se han avanzado propuestas sugiriendo clonar individuos de gran capacidad intelectual o artística, o de virtud eminente. Tales propuestas utópicas son sumamente desafortunadas. No es posible clonar un individuo humano, aun si se clona su genoma. De genomas idénticos, desarrollados en contextos diferentes, familiares, sociales y culturales, pueden resultar individuos totalmente diferentes. Además, entran en juego consideraciones éticas, sociales y religiosas cuando se examina si una persona puede o debe ser clonada.

PALABRAS CLAVE: Evolución humana; terapia genética; terapia germinal; clonación; ética; sociedad; cultura.

\section{HUMAN CLONING? LIMITS TO EUGENICS}

Copyright: (C) 2019 CSIC. Este es un artículo de acceso abierto distribuido bajo los términos de la licencia de uso y distribución Creative Commons Reconocimiento 4.0 Internacional (CC BY 4.0).

ABSTRACT: Mankind has not only evolved; but continues to do so. Where is human evolution going? Biological evolution is directed by natural selection, which brings about genetic changes that often appear purposeful because they are dictated by the requirements of the environment. The end result may, nevertheless, be extinction. Genetics, molecular biology and biomedicine have opened up the means to rapidly and effectively manipulate the genetic makeup of humankind. Gene therapy can be somatic or germ-line, which can correct a genetic defect, not only in the organs or tissues impacted, but also avoid transmission of the genetic impairment to the descendants. No interventions of germ-line therapy are currently being considered by scientists, physicians, or pharmaceutical companies. Human cloning may also refer to therapeutic cloning, particularly the cloning of embryonic cells to obtain organs for transplantation or for treating injured nerve cells, or for other health purposes. Some proposals have suggested the cloning of human individuals of great intellectual or artistic achievement or of great virtue. Such utopian proposals, however, are grossly misguided. It is not possible to clone a human individual, even if its genome is cloned. Identical genomes yield, in different familiar, social and cultural environments, individuals who may be quite different. Moreover, ethical, social, and religious values come into play when seeking to decide whether a person might be allowed to be cloned or not.

KEYWORDS: Human evolution; genetic therapy; germinal therapy; cloning; ethics; society; culture. 


\section{INTRODUCCIÓN: EL ORIGEN DE LA HUMANIDAD}

La humanidad es una especie biológica, Homo sapiens, que ha evolucionado a partir de especies que no eran humanas. Nuestros parientes próximos más cercanos son los grandes simios, sobre todo los chimpancés, que se hallan más estrechamente emparentados con nosotros que con los gorilas, y mucho más que con los orangutanes. Las especies de nuestro linaje, una vez que se separó del linaje que va a los chimpancés, se llaman homininos. El linaje de los homininos divergió del linaje del chimpancé hace 6-7 millones de años (Ma) y evolucionó exclusivamente en el continente africano hasta la aparición de Homo erectus en algún momento anterior a hace 1,8 Ma.

Los fósiles de homininos más antiguos que se conocen tienen entre 6 y 7 millones de años de antigüedad, proceden de África, y son conocidos como Sahelanthropus y Orrorin (o Preanthropus). Estos antepasados eran predominantemente bípedos cuando estaban en tierra pero tenían cerebros muy pequeños. El Ardipithecus vivió hace unos 4,4 millones de años, también en África. Numerosos restos fósiles de diversos orígenes africanos se conocen del Australopithecus, un hominino que apareció entre hace 3 millones y 4 millones de años. El Australopithecus tenía una postura erguida humana pero una capacidad craneal de menos de 500 cc (centímetros cúbicos), comparable a la del gorila o el chimpancé y de más o menos un tercio de la de los humanos modernos (500 cc son equivalentes a 500 gramos). La cabeza del Australopithecus exhibía una mezcla de características simias y humanas: una frente baja y un largo rostro simiesco pero con dientes proporcionados como los de los humanos. Otros primeros homininos parcialmente contemporáneos del Australopithecus incluyen al Kenyanthropus y el Paranthropus; ambos poseían cerebros comparativamente pequeños, aunque algunas especies de Paranthropus poseían cuerpos más grandes. El Paranthropus representa una rama lateral del linaje hominino que se extinguió.

Junto con una capacidad craneal mayor, se han encontrado otras características humanas en el Homo habilis, que vivió entre hace unos 2,5 millones y 2 millones de años en África y tenía una capacidad craneal de algo más de 600 cc (o 600 gramos), y en el Homo erectus, que evolucionó en África hace algo más de 1,8 millones de años y poseía una capacidad craneal de 800 a 1.100 cc (desde casi 800 gramos a casi un kilo y cien gramos). El Homo erectus es el primer migrante intercontinental que hubo entre nuestros antepasados homininos. Poco después de su aparición en África, el Homo erectus se esparció por Europa y Asia, hasta llegar incluso al archipiélago indonesio y China septentrional. Se han hallado restos fósiles del Homo erectus en África, Indonesia (Java), China, Oriente Medio y Europa. Los fósiles del Homo erectus procedentes de Java se han fechado en 1,81 y 1,66 millones de años de antigüedad, y los de Georgia (en Europa, cerca de la frontera asiática) entre 1,6 y 1,8 millones de años.

Varias especies de homininos vivieron en África, Europa y Asia hace entre 1,8 millones y 500.000 años, conocidos como Homo ergaster, Homo antecessor, y Homo heidelbergensis, con tamaños cerebrales aproximadamente idénticos a los del Homo erectus. Algunas de estas especies fueron en parte contemporáneas, aunque vivieron en diferentes regiones del Viejo Mundo. Estas especies se incluyen a veces bajo el nombre de Homo erectus (en sentido lato).

La transición de Homo erectus a Homo sapiens podría haber empezado en África tropical o subtropical hace unos 400.000 años. Algunos fósiles de esa época parecen formas "arcaicas" del Homo sapiens. Sin embargo, el Homo erectus persistió hasta hace 250.000 años en China y tal vez hasta hace 100.000 años en Java. La especie Homo neanderthalensis apareció en Europa hace más de 200.000 años y persistió hasta hace 30.000 años. Se ha creído que los neandertales eran antepasados de humanos anatómicamente modernos, pero ahora sabemos que los humanos modernos aparecieron en África hace más de 100.000 años y colonizaron Europa hace más de 60.000 años, mucho antes de la desaparición de los fósiles neandertales. Las comparaciones del ADN de los fósiles neandertales con humanos actuales indican que algunos cruces se produjeron entre los neandertales y sus contemporáneos de Homo sapiens. Aproximadamente el $2 \%$ del genoma de los humanos actuales proviene de antepasados neandertales.

\section{EVOLUCIÓN BIOLÓGICA: PASADO Y FUTURO}

El descubrimiento de la evolución del ser humano a partir de antepasados no humanos es quizá la contribución más importante de las ciencias naturales al conocimiento de la naturaleza humana. El ser humano sabe ahora que no siempre fue como es hoy, que su naturaleza biológica ha cambiado radicalmente desde que el primer individuo de nuestra especie inició su existencia hace unos cuantos miles de años. La naturaleza biológica de la humanidad no solo ha evolucionado, sino que continúa evolucionando todavía. La afirmación que se hace a veces de que la evolución de la humanidad se ha detenido carece de fundamento. 
Existe asimismo la posibilidad de que la humanidad dirija su propia evolución, de que dentro del proceso de cambio de la naturaleza humana se introduzcan proyectos y objetivos humanos. Los descubrimientos de las ciencias biomédicas, y en particular de la genética y la biología molecular, han facilitado la comprensión de las vías y medios para manipular de un modo rápido y eficiente la constitución genética de la humanidad, y han abierto la posibilidad de llevar a cabo tales manipulaciones.

La selección natural es el proceso de reproducción diferencial de variantes genéticas alternativas que da cuenta de la evolución de los organismos. Algunos biólogos, sociólogos y otros -notablemente entre ellos el genético premio Nobel $\mathrm{H}$. J. Muller- han afirmado que la selección natural ya no ocurre en nuestra especie. Se afirma que los avances de la medicina, la higiene y la nutrición han eliminado en gran parte la muerte antes de la edad madura; es decir, la mayoría de personas viven más allá de la edad reproductiva, después de la cual la muerte ya no tiene consecuencias para la selección natural.

Que la humanidad continúa evolucionando biológicamente puede demostrarse porque persisten las condiciones necesarias y suficientes para la evolución biológica. Dichas condiciones son: variabilidad genética y reproducción diferencial. Hay muchísima variación genética en la especie humana. Con la excepción de los gemelos idénticos, que se desarrollan a partir de un único óvulo fecundado, no es probable que haya dos personas que vivan en la actualidad, que hayan vivido en el pasado o que vayan a vivir en el futuro que sean idénticas desde el punto de vista genético. Gran parte de esta variación es relevante para la selección natural.

\subsection{Selección natural: mortalidad y fecundidad}

¿Se da selección natural en la humanidad moderna? La selección natural, como se ha indicado, es simplemente reproducción diferencial de variantes genéticas alternativas. Por lo tanto, se producirá en la especie humana si los portadores de algunos genotipos tienen probabilidades de dejar más descendientes que los portadores de otros genotipos. La selección natural consiste en dos componentes principales: mortalidad diferencial y fecundidad diferencial. Ambos persisten en la humanidad moderna, aunque la intensidad de la selección debida a la mortalidad postnatal se haya atenuado algo.

La muerte puede tener lugar entre la concepción y el nacimiento (prenatal) o después del parto (postna- tal). La muerte durante las primeras semanas del desarrollo embrionario puede pasar totalmente inadvertida. Pero se sabe que por lo menos el $20 \%$ de todas las concepciones humanas terminan en aborto espontáneo durante los dos primeros meses de embarazo. Estas muertes suelen deberse a constituciones genéticas deletéreas, y por lo tanto tienen un efecto selectivo favorable en la población. La intensidad de esta forma de selección no ha cambiado sustancialmente en la humanidad moderna, aunque se ha reducido algo con respecto a unos pocos genes, como los implicados en la incompatibilidad del grupo sanguíneo Rh.

En los países técnicamente avanzados, la mortalidad postnatal se ha reducido considerablemente en épocas recientes. Por ejemplo, en los Estados Unidos, de las personas nacidas en 1840 algo menos del 50 por ciento sobrevivían hasta la edad de 45 años, mientras que la esperanza media de vida para las personas nacidas en 1960 es de 78 años. En otras regiones del mundo, la mortalidad postnatal sigue siendo muy alta, aunque en general se ha reducido en las últimas décadas. La mortalidad antes del final de la edad reproductora, en particular allí donde se ha reducido considerablemente, se halla asociada en gran parte a defectos genéticos, y así tiene un efecto selectivo favorable en las poblaciones humanas. Se conocen más de 4.000 variantes genéticas que causan enfermedades y malformaciones en los humanos. Tales variantes se mantienen en frecuencias bajas debido a la selección natural.

En principio, podría parecer que la selección natural debida a la fecundidad diferencial se ha reducido considerablemente en los países industriales como consecuencia de la disminución del número medio de hijos por familia que se ha dado en tiempos recientes, particularmente en países económicamente desarrollados. Sin embargo, ello no es así. La intensidad de la selección de fecundidad no depende del número medio de hijos por familia, sino de la varianza (en el sentido técnico usado en estadística, que es una manera de estimar la variación) en el número de hijos por familia. Es evidente por qué debe ser así. Supóngase que todas las personas en edad reproductiva se casan y que todas tienen exactamente el mismo número de hijos. En este caso, no habría selección natural debida a la fecundidad, tanto si todas las parejas tuvieran muy pocos, como si tuvieran muchos hijos. Supóngase, en cambio, que el número medio de hijos por familia es bajo, pero que algunas familias no tienen ningún hijo, mientras que otras tienen muchos. En este caso, habrá una oportunidad considerable de selección: los genotipos de los padres que producen muchos hijos aumentarían en frecuencia 
a expensas de los que producen pocos o ninguno. Los estudios de poblaciones humanas han demostrado que la oportunidad de la selección natural suele aumentar a medida que se reduce el número medio de hijos. Un extenso estudio publicado en 1958 (véase tabla 1) demostraba que el índice de oportunidad para la selección debida a fecundidad era cuatro veces mayor entre las mujeres de los Estados Unidos nacidas en el siglo XX, con una media de menos de tres hijos por mujer, que entre las mujeres de Ghana o del Quebec rural, que por término medio tenían más de seis hijos. No hay pruebas de que la selección natural debida a la fecundidad haya disminuido en las poblaciones humanas modernas.

I se calcula como la varianza dividida por el cuadrado del número medio de hijos. La oportunidad para la selección aumenta en general a medida que disminuye el número medio de hijos (Crow, 1958).

La selección natural puede reducirse en intensidad en el futuro, pero no desaparecerá completamente. Mientras haya variación genética y los portadores de determinados genotipos tengan más probabilidad de reproducirse que otros, la selección natural continuará. Los cambios culturales, como el desarrollo de la agricultura, la migración desde el campo a las ciudades, la contaminación ambiental y muchos otros, crean nuevas presiones de selección. Las tensiones de la vida en la ciudad son en parte responsables de la elevada incidencia de trastornos mentales en determinadas sociedades humanas. Lo que hay que tener presente es que los ambientes humanos están cambiando más rápidamente que nunca, debido precisamente a la tasa acelerada del cambio cultural; y los cambios ambientales crean nuevas presiones se selección, que fomentan la evolución biológica.

\subsection{Diversidad genética}

La selección natural actúa favoreciendo ciertas variantes genéticas a costa de otras. Es decir, para que haya selección natural tiene que haber variación entre los genotipos de diversos individuos. Considerando un gen por separado, se da variación genética cuando en la población se presentan dos o más alelos en ese gen (los alelos son las formas variantes de un gen determinado). ¿Cuánta variación genética existe en la población humana actual? La respuesta es: muchísima; pero la selección natural solo tendrá lugar si los alelos de un gen dado tienen efectos diferentes sobre la eficacia reproductiva, es decir, si los alelos alternativos afectan de manera diferencial a la probabilidad de supervivencia y reproducción.

Se estima que los dos genomas que heredamos de cada progenitor difieren en aproximadamente 1 o 2 nucleótidos de cada mil (nucleótidos son los componentes unitarios, asociados en pares, que constituyen el DNA hereditario). El genoma humano, es decir, el ADN de un individuo, consta de algo más de 3.000 millones de nucleótidos. Así, del orden de 3 a 6 millones de nucleótidos son diferentes entre los dos genomas de cada individuo humano (uno heredado del padre y otro de la madre), que es una gran cantidad de polimorfismo genético. Además, el proceso de mutación introduce nueva variación en cualquier población en cada generación. Se estima que la tasa de mutación en el genoma humano es de alrededor de $10^{-8}$, una mutación en un nucleótido por cada 100 millones de nucleótidos, o cerca de 30 mutaciones nuevas por genoma y por generación. Así, cada humano tiene unas 60 mutaciones nuevas (30 en cada genoma, heredados uno del padre, y otro de la madre) que no estaban presentes en sus padres. Si considera-

Tabla 1. Número medio de hijos por familia y oportunidad para la selección por fertilidad, $I_{f}$, en diversas poblaciones humanas

\begin{tabular}{|l|c|c|}
\hline Población humana & Número medio de hijos & $I_{f}$ \\
\hline Zona rural de Quebec (Canadá) & 9,9 & 0,20 \\
\hline Costa de Oro (África) & 6,5 & 0,23 \\
\hline Nueva Gales del Sur & 6,2 & 0,42 \\
\hline Estados Unidos, mujeres nacidas en 1839 & 5,5 & 0,23 \\
\hline Estados Unidos, mujeres nacidas en 1871-1875 & 3,5 & 0,71 \\
\hline Estados Unidos, mujeres nacidas en 1928 & 2,8 & 0,45 \\
\hline Estados Unidos, mujeres nacidas en 1909 & 2,1 & 0,88 \\
\hline Estados Unidos, indios navajos & 2,1 & 1,57 \\
\hline
\end{tabular}


mos la población humana total, eso sube a 60 mutaciones por persona multiplicadas por más de 7.000 millones de personas, o más de 420.000 millones de nuevas mutaciones por generación, que se añaden a los millones de nucleótidos polimórficos (diferentes entre el genoma heredado del padre y el de la madre) preexistentes.

Son muchísimas mutaciones, pero hemos de recordar que los polimorfismos que cuentan para la selección natural son los que afectan a la probabilidad de supervivencia y reproducción de sus portadores. El resto de los nucleótidos variantes pueden aumentar o disminuir en frecuencia por azar, un proceso que los evolucionistas llaman deriva genética, pero que no tiene consecuencia con respecto a la selección natural. Se dan muchos genes en nuestra especie, cuyas formas alternativas (alelos) pueden ser uno más beneficioso que el otro, al menos en ciertos ambientes, sin que se pueda decir que el alelo menos beneficioso cause enfermedad o defecto. Dos ejemplos fáciles de identificar son el gen que codifica la lactosa y el gen o genes que codifican la melanina. La lactosa permite digerir la leche y, por ello, el gen que codifica la lactosa es beneficioso en países que cultivan ganado de leche. La melanina protege del sol que en países tropicales aumenta la incidencia del melanoma, cáncer de la piel. Pero el enfoque en el presente trabajo es la ingeniería, es decir, los métodos para remediar los genes que causan enfermedades y otros defectos. Así pues, es de estos genes de los que debemos ocuparnos.

\subsection{Genes y enfermedades}

En las poblaciones humanas se han identificado más de 4.000 enfermedades, malformaciones y otros defectos, cuya causa es genética. Los trastornos genéticos pueden ser, de acuerdo con la terminología de la genética, dominantes, recesivos, multifactoriales o cromosómicos. Los trastornos dominantes son causados por la presencia de una única copia del gen defectivo, heredado de solo uno de los padres, de manera que el trastorno se expresa en los individuos heterocigotos, los que poseen un gen (alelo) normal y uno defectivo. En los trastornos recesivos, el alelo defectuoso ha de estar presente en ambos genomas; es decir, se hereda de cada progenitor. (En el caso de genes en el cromosoma $X$, dado que los varones tenemos solo un cromosoma $X$, se expresan en ellos tanto las mutaciones recesivas como las dominantes). Los trastornos multifactoriales son causados por interacciones entre varios genes, a veces localizados en diferentes cromosomas. Y los trastornos cromosómicos se deben a la presencia o ausencia de un cromosoma entero o de un fragmento de cromosoma.
Ejemplos de trastornos dominantes son algunas formas de retinoblastoma y otros tipos de ceguera, el enanismo acondroplástico ${ }^{1}$ y el síndrome de Marfan (que se cree que afectó al presidente Lincoln de los Estados Unidos). Ejemplos de trastornos recesivos son la fibrosis quística, la enfermedad de Tay-Sachs y la anemia falciforme (causada por un alelo que en condiciones heterocigóticas protege contra la malaria). Son ejemplos de enfermedades multifactoriales la espina bífida y el paladar hendido. Entre los trastornos cromosómicos más comunes está el síndrome de Down, causado por la presencia de un cromosoma 21 extra, y varios tipos de trastornos debidos a la ausencia de un cromosoma sexual o a la presencia de uno adicional, más allá de la condición normal de XX para las mujeres y de $X Y$ para los hombres. Son ejemplos el síndrome de Turner (XO) y el síndrome de Klinefelter (XXY).

Se estima que la incidencia de trastornos genéticos en la población humana actual es de no menos del 2,56 por ciento y afecta a unos 180 millones de personas. La selección natural reduce la incidencia de los genes que causan enfermedad, de manera más efectiva en el caso de los trastornos dominantes, en los que todos los portadores del gen expresaran la enfermedad, que en los trastornos recesivos, que solo se expresan en los individuos homocigotos (es decir, con dos copias del gen defectivo, heredadas una del padre y la otra de la madre, como se dijo anteriormente). Considérese, por ejemplo, la fenilcetonuria, conocida como PKU, una enfermedad hereditaria, debida a la incapacidad de metabolizar el aminoácido fenilalanina, que se manifiesta por una deficiencia intelectual grave y trastornos neurológicos. La fenilcetonuria es letal si no se trata. Tiene una incidencia de 1 de cada 10.000 recién nacidos, es decir, del 0,01 por ciento. La frecuencia del alelo es de un 1 por ciento, de modo que en condición heterocigótica se halla presente en más de 70 millones de personas, pero solo el 0,01 por ciento, es decir unas 700 mil personas, son homocigotos y, por tanto, expresan la enfermedad y se hallan sujetas a la selección natural. La reducción de los trastornos genéticos debido a la selección natural está compensada por su aumento debido a la incidencia de nuevas mutaciones.

\section{4. Futuro biológico}

La evolución biológica es dirigida por la selección natural, que no es un proceso benevolente que guíe a las especies hacia un éxito seguro. El resultado final puede ser la extinción. Más del 99,9 por ciento de todas las especies que existieron desde el origen de la vida sobre la tierra se han extinguido. La selección 
natural no tiene ningún propósito; solo los humanos tienen propósitos y solo los humanos pueden introducir propósitos en la evolución.

No ha habido ninguna especie antes de la humanidad que pudiera seleccionar su propio destino evolutivo; la especie humana puede hacerlo, y ya se dispone de técnicas potentes para el cambio genético directo. Puesto que tenemos consciencia de nosotros mismos, los humanos no podemos dejar de preguntarnos qué nos deparará el futuro, y puesto que somos seres éticos, debemos elegir entre vías de acción alternativas, algunas de las cuales pueden parecer buenas, y otras malas. Los avances en conocimientos de genética, biología molecular, medicina y técnicas asociadas se usarán seguramente en el futuro de manera mucho más extensa y agresiva que ahora. Se ha sugerido que tales progresos podrían utilizarse para "mejorar" nuestra constitución genética, con el fin de producir seres humanos muy superiores a nosotros. Sin embargo, existen buenas razones por las que cualquier intento de mejorar la constitución genética de la humanidad, excepto en el sentido de curar enfermedades y defectos, puede no ser prudente.

Hay quienes anticipan que el uso de la eugenesia, aun cuando lo sea para corregir enfermedades y defectos, puede tener consecuencias perjudiciales para la humanidad a largo plazo. En condiciones naturales, es decir, sin la intervención de la medicina y de la cirugía genética, las mutaciones dañinas son eliminadas de la población con mayor o menor rapidez dependiendo de la gravedad del daño que causen. En general, una mutación es eliminada más rápidamente cuanto más perjudicial sea su efecto en las personas que la poseen. Pero a causa de la intervención médica y de las terapias genéticas, ciertas mutaciones dañinas han dejado de ser eliminadas o, al menos, no son eliminadas con tanta rapidez y eficacia como en el pasado.

Consideremos el caso de la fenilcetonuria, una enfermedad debida a la incapacidad de metabolizar el aminoácido fenilalanina, como se indicó anteriormente. La fenilalanina se acumula en el organismo y se hace tóxica para el cerebro, causando incapacidad mental y eventualmente la muerte durante la infancia. Con una dieta apropiada, el niño puede llegar a ser adulto y llevar una vida prácticamente normal. Si el paciente tiene hijos, pasará sus genes PKU a ellos, que no padecerán la enfermedad si el otro progenitor no lleva el gen PKU. En consecuencia, el gen aumentará en frecuencia de generación en generación. Cuantos más pacientes se curen más habrá que curar en el futuro. ¿Con qué rapidez aumentará la frecuencia del gen? No necesitamos entrar aquí en los detalles de las ecuaciones que describen estos procesos. Baste decir que si se curase a todos los pacientes PKU en el mundo, la frecuencia del gen aumentaría de 0.01 a 0.02 en cien generaciones y que el número de pacientes aumentaría de 1 en 10.000 a 4 en 10.000. No hay que menospreciar las exigencias de curar al número creciente de pacientes, pero desde el punto de vista de la población humana el aumento no es drástico. Además cabe pensar en el progreso de la medicina y de la ingeniería genética a través del tiempo. Al presente, cien generaciones requieren 3.000 años. Pensando que la ingeniería genética tiene menos de cuatro décadas de existencia, es fácil imaginarse que muchísimos años antes de llegar a la duplicación de la frecuencia del gen PKU, se habrán descubierto tecnologías que curarían la enfermedad al nivel genético y el gen sería así eliminado de la población.

Consideremos ahora otra dolencia genética cuya herencia es de tipo diferente a la anterior. El retinoblastoma es una enfermedad cancerosa causada por una mutación genética. Pero se trata de un gen dominante, es decir, que todos los portadores del gen sufren de la enfermedad, en vez de ser un gen recesivo como el PKU que hay que heredarlo de ambos padres para sufrir la enfermedad. El gen responsable del retinoblastoma se conoce como RB1 y reside en el cromosoma 13. (Los humanos tenemos 23 pares de cromosomas). El retinoblastoma es una enfermedad cancerosa de la retina, que tiene manifestaciones un tanto variables. Típicamente, durante le infancia se produce un crecimiento tumoral que empieza primero en uno de los ojos, se extiende rápidamente al otro y, por fin, al cerebro, causando la muerte del individuo, por lo común antes de la pubertad. Si el retinoblastoma se diagnostica a tiempo es posible salvar la vida del niño por medio de una operación quirúrgica, aunque la pérdida de uno o incluso de los dos ojos es en general inevitable. La cura es eficaz en el 95-98 por ciento de los casos. La persona curada puede llevar una vida más o menos normal, casarse y tener hijos, pero la mitad de estos nacerán con retinoblastoma y necesitarán del tratamiento quirúrgico a su vez. Antes de que el progreso médico hiciera posible la cura, las mutaciones del retinoblastoma que aparecían en las poblaciones humanas eran eliminadas con la muerte de sus portadores. En el momento presente, las nuevas mutaciones que surgen en cada generación van sumándose a las que tuvieron lugar en generaciones anteriores y han sido transmitidas a los descendientes gracias a la cirugía que detuvo la enfermedad en los retinoblastómicos. Se estima que se dan aproximadamente dos casos por cada cien mil recién nacidos, que es el doble de la frecuencia de nacimientos con PKU. La 
diferencia importante desde el punto de vista presente con respecto a PKU, es que si los pacientes curados de retinoblastoma se casan y tienen hijos, el número de casos se doblará más o menos en cada generación.

Se conocen unas 4.000 dolencias cuya causa es, al menos en parte, genética. Hay bastantes dolencias hereditarias cuya manifestación puede curarse hoy en día de manera parcial o total y el número de las que cuentan con tratamiento clínico aumenta con rapidez. En la mayoría de los casos, las personas curadas pueden casarse y tener descendientes; pero, como se ha anotado, cuantas más dolencias con causa genética se curen hoy, tanto mayor será el número de ellas que tendrán que ser objeto de tratamiento médico en sucesivas generaciones. El dilema es claro. Si es posible curar, las consideraciones morales implican la obligación de hacerlo. Como escribió el gran genético evolucionista Theodosius Dobzhansky:

"Si permitimos que los débiles y deformes vivan y propaguen sus caracteres, nos enfrentamos con la perspectiva de un ocaso genético. Pero si los dejamos morir o sufrir cuando podemos salvarlos o ayudarlos, nos hallamos frente a la certidumbre de un ocaso moral" (Dobzhansky, 1973).

El problema resulta aún más acuciante cuando se consideran los trastornos mentales. Se ha estimado que cerca del 1 por ciento de la población sufre de esquizofrenia o de lo que se llama enfermedad esquizoide; unas enfermedades que pueden estar determinadas por una sola o varias mutaciones genéticas (aunque no se hayan identificado tales genes). Hacia el 3 por ciento de la población humana sufre de retraso mental (IQ menor de 70), condición determinada poligénicamente, es decir, mediante la interacción de múltiples genes (y, por tanto, mucho más difícil de corregir con métodos de ingeniería genética; de hecho, imposible en el estado actual de las técnicas). En conjunto, cerca de 300 millones de personas en el mundo sufren de defectos o enfermedades mentales causadas por su herencia biológica. Muchas de tales personas no podrían sobrevivir en las condiciones de una civilización primitiva, mientras que hoy en día lo hacen y se reproducen. Un aumento, por pequeño que sea, de individuos con dolencias y defectos genéticos es intrínsecamente indeseable tanto por el sufrimiento de sus portadores y parientes como por la carga social que supone. Pero la alternativa es peor: consiste en negar la cura a los ya nacidos y dejarles que sufran o mueran. Algo por completo inaceptable en términos éticos, siempre que existan y sean accesibles los medios para combatir la enfermedad.

\section{TERAPIA GENÉTICA}

Las propuestas de mejora de la condición humana por medio de la llamada eugenesia o ingeniería genética, es decir, usando los conocimientos de la genética molecular y las técnicas y prácticas asociadas con ella, pueden agruparse en dos categorías generales con respecto a sus objetivos. Por un lado, están las propuestas terapéuticas, que se plantean corregir enfermedades o defectos y aliviar el dolor y el sufrimiento tanto individual como social. Por otro, están las visiones utópicas que persiguen un "mundo feliz", por medio de la mejora de genes o la clonación de individuos con genotipos idóneos, para alcanzar una humanidad ideal y perfecta o, al menos, lo más perfecta posible. Entre las consideraciones terapéuticas están la diagnosis y el consejo genético, la farmacopea genética y la cirugía genética. Entre las propuestas utópicas se encuentran la selección germinal y la clonación de individuos.

Existen ahora en muchos países -y su número crece- clínicas genéticas y consultorios médicos cuyo propósito es el de descubrir la presencia de defectos genéticos crípticos en quienes van a ser padres para aconsejarles respecto de la probabilidad de que esos defectos genéticos se manifiesten en sus hijos. Como defectos genéticos crípticos se incluye la presencia de un gen defectivo asociado con uno normal en el caso de los genes recesivos, es decir, cuando el carácter solo se manifiesta si el gen defectivo se ha heredado tanto del padre como de la madre. Por ejemplo, un individuo portador de un alelo de fenilketonuria cuyo par es normal no padece la PKU, pero transmitirá ese alelo a la mitad de sus descendientes. Si su pareja es también portadora de un gen PKU, existe una probabilidad del 25 por ciento de que cada hijo que tengan sufra la PKU (la probabilidad de que el hijo haya heredado el alelo PKU de la madre es 0,50; que la herede del padre es también 0,50; que la herede de los dos es $0,50 \times 0,50=0,25$ ).

Las personas que acuden a tales clínicas y consultorios son aquellas que tienen razones para sospechar que son portadores de algún defecto genético críptico. Tal es el caso de personas con familiares en los que el defecto es manifiesto. Por ejemplo, es probable que un hermano o un tío de una persona con PKU sea portador del gen defectivo. Pero hay otras razones para ir a un consultorio genético, como es el caso de las madres de 35 años de edad o más, cuyas probabilidades de concebir hijos con defectos cromosómicos son altas. Por ejemplo, la probabilidad de que una mujer de menos de 30 años tenga un hijo con síndrome de Down es de menos de uno por mil. A partir de esa 
edad, la probabilidad aumenta rápidamente, llegando a un uno por cien a los cuarenta años y a uno por cincuenta a los 45. El síndrome de Down se debe a la presencia de tres copias del cromosoma 21 en vez de las dos copias normales. El síndrome de Turner y el síndrome de Klinefelter son otros ejemplos de anormalidades cromosómicas serias cuya incidencia aumenta muy deprisa con la edad de la madre.

En las clínicas con tecnología apropiada se puede analizar la constitución genética de los padres para comprobar si son o no portadores de genes o de cromosomas defectivos. Es posible calcular así la probabilidad de que un hijo vaya a sufrir la enfermedad, como en el ejemplo de PKU citado antes. Los futuros padres pueden decidir no tener hijos o arriesgarse a tener uno anormal. Pero es posible ir incluso más allá. Las técnicas como la amniocentesis (del griego amnion, membrana y kentesis, perforación) permiten descubrir si el feto posee o no características genéticas indeseables. La amniocentesis se lleva a cabo insertando una aguja larga a través del abdomen de la madre encinta para obtener una muestra pequeña de fluido amniótico, que es el líquido en el que flota el feto. Por medio del análisis microscópico y químico de las células epiteliales del feto obtenidas del fluido es posible identificar en muchos casos los defectos genéticos.

Si se determina que el feto posee una constitución genética indeseable, los padres pueden optar por el aborto. Es esta una decisión con implicaciones morales y religiosas y, en algunos países, incluso con repercusiones legales. Y por supuesto no todos los padres estarán de acuerdo en proceder al aborto. Un caso bien conocido es el de Sarah Palin, que fue candidata para la vice-presidencia de los Estados Unidos en el año 2008. Frecuentemente, aparecía en público con el menor de sus hijos en los brazos. Cuando todavía estaba encinta había sabido que el niño nacería con el síndrome de Down, pero por razones religiosas decidió no abortar. Investigar si los padres son portadores de un defecto genético o si el feto expresará tal defecto son prácticas apropiadas solo cuando hay razones para sospechar la presencia de un defecto genético en particular, como en los casos ya citados. Varios centenares de anomalías genéticas podrían ser descubiertas analizando las células de los padres o por medio de la amniocentesis, pero los costes y el uso apropiado de recursos técnicos solo justifican el análisis cuando hay alguna razón seria para ello.

Los diabéticos necesitan inyectarse la hormona insulina para poder digerir la azúcar que, sin ella, se acumula en el organismo con efectos debilitantes y hasta fatales. La insulina es una proteína sintetizada en el páncreas. Durante muchos años, la compañía farmacéutica Eli Lilly extrajo y purificó la insulina del páncreas de los cerdos y del ganado vacuno. Aunque no idéntica del todo a la humana, esta insulina sirve como tratamiento satisfactorio para la mayoría de los diabéticos. Pero en 1982, Lilly introdujo en el mercado Humulin, una insulina idéntica a la humana porque está sintetizada precisamente bajo el control del gen humano de la hormona. La producción de insulina humana fue el primer éxito farmacéutico en gran escala de la ingeniería genética, una tecnología emergente que llegó de la mano de los avances de la genética molecular: la venta anual de Humulin alcanza más de tres mil millones de euros.

Los elementos esenciales del proceso de ingeniería genética llamado $A D N$ recombinante pueden explicarse sin muchas complicaciones. El gen de la insulina extraído de un páncreas humano es introducido en un plásmido, que es una cadena circular de ADN. El plásmido que contiene el gen es introducido a su vez en bacterias inofensivas y fáciles de multiplicar en un laboratorio apropiado. Cuando las bacterias se multiplican, sintetizan las proteínas codificadas por sus propios genes, como es lógico, pero también la insulina codificada por el gen introducido que las bacterias tratan como si fuera uno de los suyos. La insulina extraída de grandes masas de estas bacterias es idéntica a la insulina humana y funciona de manera tan eficaz como la original, sin las dificultades creadas en ciertos pacientes por la insulina extraída del cerdo o de ganado.

A partir de 1982, los éxitos de la ingeniería genética en la producción de hormonas, proteínas y otros productos biológicos de beneficio farmacéutico aumentaron a gran velocidad. Uno de los éxitos más inmediatos fue la producción de somatotropina, la hormona humana del crecimiento (hGH, human Growth Hormone). La hGH se produce en la glándula pituitaria del cerebro, de donde pasa a la circulación sanguínea con influencia en los tejidos y órganos del individuo. La deficiencia de hGH en los niños detiene su crecimiento y da como resultado el enanismo, pero además causa en los adultos una fatiga extrema, ansiedad, depresión y malestar general. Aproximadamente tres de cada diez mil adultos sufren deficiencias de hGH. La hGH extraída del ganado vacuno o de otros animales no es efectiva en los humanos. Hacia mediados del siglo XX, se obtenía en cantidades minúsculas de la pituitaria de individuos jóvenes y sanos 
fallecidos en accidente. Pero dada la escasez de hGH, solo unos pocos niños podían ser tratados para corregir algo su enanismo.

El gen de la somatotropina fue integrado por primera vez en las bacterias en 1979 usando las técnicas de ADN recombinante, que obtuvieron la hormona llamada por esa razón rhGH. En 1985, la rhGH fue introducida en el mercado, pero en esa ocasión sin límites cuantitativos. Había rhGH suficiente para curar a los niños que habrían terminado siendo enanos sin la hormona original y también para curar adultos con deficiencias en la hGH causadas por ciertos tumores y otras enfermedades de la glándula pituitaria. Pero también apareció un uso no medicinal de la rhGH: igual que en el caso de otros esteroides, la hormona aumenta la masa muscular. Su administración a los atletas ha llevado a tropezar con los comités olímpicos y deportivos y, en general, al rechazo público.

La ingeniería genética ha producido durante las dos últimas décadas un gran número de hormonas, enzimas, factores antihemofílicos, anticuerpos monoclonales que evitan el rechazo de los trasplantes, interferones para controlar la leucemia, la hepatitis y la esclerosis múltiple, activadores plasminógenos para tratar los infartos y muchos otros fármacos de grandes beneficios para la humanidad.

\subsection{Cirugía genética o eugenesia}

La medicina utiliza medicamentos diversos para curar enfermedades: muchos de ellos derivados de las plantas y de los animales; otros, sintetizados en el laboratorio mediante procesos químicos. Algunos de estos medicamentos son proteínas, como la insulina administrada a los diabéticos y los factores de coagulación administrados a los hemofílicos. La diferencia entre tales medicamentos y la cirugía genética consiste en que esta última administra al enfermo no la sustancia necesaria sino el ADN que permite al individuo sintetizar de manera continua en sus propias células las proteínas, enzimas y otros componentes necesarios en vez de tener que ingerirlos o recibirlos mediante una inyección repetidamente. Caben pocas dudas acerca de que los tratamientos de la terapia genética, los que ya se usan con éxito y los muchos más que con seguridad serán aprobados en el futuro, son beneficiosos para la humanidad. Cambiarán a ciencia cierta las prácticas médicas del futuro.

La denominación cirugía genética se refiere, pues, a las técnicas usadas para corregir defectos en el ADN de los humanos. La cirugía genética podría llamarse también terapia genética, pero esta categoría es más amplia: se incluyen en ella tanto la diagnosis y consejo genéticos como la producción de fármacos discutidos en las páginas anteriores. La cirugía genética consiste, de manera precisa, en la manipulación directa del material hereditario (ADN) humano usando las técnicas de ADN recombinante. El descubrimiento de las técnicas de ADN recombinante y sus primeras aplicaciones a bacterias datan de principios de la década de 1970. Su aplicación experimental a los seres humanos comenzó hacia fines de los años ochenta del siglo pasado.

Consideremos, por ejemplo, la mutación responsable de la anemia falciforme. La hemoglobina de las personas que sufren anemia falciforme es incapaz de transportar con eficacia el oxígeno desde los pulmones hasta el resto del cuerpo, donde sirve de comburente en las reacciones químicas que constituyen las funciones vitales. Las personas que sufren de anemia falciforme mueren, por lo general, antes de alcanzar la madurez. La enfermedad se debe a un defecto en la cadena $\beta$, una de las dos proteínas ( $\alpha$ y $\beta$ ) que constituyen el 98 por ciento de la hemoglobina de los humanos adultos. Las cadenas $\alpha$ y $\beta$ están determinadas cada una por un gen diferente. La cadena beta $(\beta)$ consta de 146 aminoácidos consecutivos; el sexto aminoácido es el ácido glutámico en la hemoglobina normal y la valina en la hemoglobina falciforme. Si por mutación en el gen de la cadena $\beta$ se cambia una letra de ese triplete en particular (un nucleótido de los 438 que codifican sus 146 aminoácidos), la hemoglobina final tendrá en ese lugar preciso el aminoácido valina en vez del ácido glutámico. Tal cambio de una sola letra en el ADN tiene consecuencias fatales. Pero si fuera posible sustituir el nucleótido mutante por el normal, la hemoglobina y el individuo funcionarían de manera adecuada.

La cirugía genética tiene precisamente este objetivo: rectificar la información genética del individuo reemplazando el ADN defectuoso por ADN normal. La operación se puede llevar a cabo sustituyendo un nucleótido por otro, o el gen anormal completo por el normal. El procedimiento hoy en uso consiste en insertar un gen adicional no mutante con el que la persona puede producir hemoglobina normal (aunque si el gen anormal no ha sido neutralizado, seguirá produciendo también la hemoglobina anémica). El primer paso consiste en incorporar el gen deseable en un plásmido, la cadena circular corta de ADN ya mencionada antes, que tiene la propiedad de introducirse en el ADN de otros organismos. El segundo paso consiste en la introducción en sí misma, tras la cual el nuevo gen se expresa en el organismo (es decir, funciona como si fuera un gen preexistente). 
La cirugía genética se aplica a las células y tejidos en los que se expresa el gen deficiente, con lo que el organismo puede llevar a cabo las funciones normales. Pero si (como hasta ahora es siempre el caso) no se corrige el gen en las células germinales -óvulos o espermatozoides-, el individuo transmitirá el gen anormal a sus descendientes. Es esa la situación que, como hemos visto, más preocupa a quienes, como Muller, se oponen a la ingeniería genética paliativa. La incidencia del gen anormal y el número de individuos que habrá que curar aumentarán de generación en generación.

En principio, la cirugía genética podría usarse para rectificar las células germinales, con lo que el individuo transmitiría a sus descendientes unos genes con funciones normales. Eso no es posible en el estado actual de la tecnología, pero es del todo imaginable en un futuro próximo. Las consecuencias para las generaciones futuras son muy diferentes en los dos casos. Si se cura solo al individuo, la incidencia de los defectos genéticos aumentará: las mutaciones de los individuos curados se suman a las nuevas mutaciones. Manipular la línea germinal humana plantea cuestiones legales y morales difíciles de resolver con las que habrá que enfrentarse cuando la cirugía genética germinal sea posible en la práctica. Por el contrario, la cirugía genética somática no conlleva implicaciones legales o morales en principio diferentes de las que plantea la práctica de la medicina común. Se trata de curar por los distintos medios disponibles a quienes sufren enfermedades o defectos.

\subsection{Presente y futuro}

El avance de terapia genética más reciente, con consecuencias potencialmente revolucionarias, es la técnica llamada Cas (abreviación en ingles de CRISPR associated; donde CRISPR son las iniciales de Clustered Regularly Interspaced Short Palindrome Repeats). CRISPR se refiere a segmentos de ADN de bacterias que incluyen repeticiones de secuencias de pocos nucleótidos (entre 24 y 48 pares). Cada una de las repeticiones está seguida por segmentos cortos de spacer ADN. Spacer es un segmento de ADN que no codifica aminoácidos. Particularmente útil es al sistema CRISPR-Cas9, en el que Cas9 es una enzima especializada en cortar ADN, que permite cortar el ADN de animales y otros organismos, incluyendo a humanos, en lugares específicos, haciendo posible "editar" genes particulares, activándolos o neutralizándolos, según se desee. En el momento actual, los expertos científicos y moralistas consideran CRISPR-Cas 9 y otros sistemas semejantes como métodos todavía experimentales, pero con enormes posibilidades futuras (Baltimore, Berg y Botchan, 2015; Doudna y Charpentier, 2014; Ledford, 2015; Morange, 2015; Slaymaker, Gao y Zetsche, 2016; Zimmerman, 2015, 15 octubre). Las posibilidades anticipadas incluyen cortar con precisión segmentos defectuosos de genes o insertar segmentos beneficiosos.

Algunos tratamientos experimentales ya se han llevado a cabo con éxito en genes causantes de enfermedades importantes como el síndrome de Parkinson, la leucemia linfática crónica, el mieloma múltiple y la hemofilia. Entre 2013 y 2014, compañías farmacéuticas americanas invirtieron más de 600 millones de dólares en terapéuticas genéticas. Las terapéuticas genéticas, además de la gran inversión económica que requerieren, frecuentemente llevan a consecuencias indeseadas. Los efectos negativos incluyen respuestas inmunes contra la inclusión de una entidad extraña, leucemia, tumores y otros problemas típicamente provocados por virus vectores. Además, frecuentemente las correcciones de terapéutica genética son de poca duración y requieren tratamientos repetidos, lo cual aumenta los costes y otros inconvenientes. Una consideración adicional es que las enfermedades genéticas más comunes son multifactoriales, causadas por interacción entre varios o muchos genes $y$, por lo tanto, más allá de las posibilidades terapéuticas actuales de la eugenesia. Ejemplos de ello son la diabetes, alta presión sanguínea, artritis, Alzhéimer y enfermedades cardiacas.

\section{CLONACIÓN DE GENES Y CÉLULAS. ¿CLONAR HUMANOS?}

Los biólogos emplean el término clonación con significados variables, aunque todos los usos implican la obtención de copias más o menos exactas de una entidad biológica. Tres usos comunes se refieren a la clonación de genes, la clonación de células y la clonación de individuos.

Clonar genes (o, de manera más general, clonar segmentos de $A D N$ ) es algo que se hace de manera rutinaria en muchos laboratorios de genética de todo el mundo. Una tecnología preferida y empleada extensamente es la PCR (reacción en cadena de la polimerasa; en inglés, polymerase chain reaction), inventada en la década de 1990 por Kary Mullis, quien recibió el premio Nobel en reconocimiento. Con la técnica de la PCR es posible obtener miles de millones de copias prácticamente idénticas de un gen o segmento de ADN en solo unas pocas horas. Esta enorme multiplicación de un segmento de ADN proporciona a 
los genetistas el material suficiente para investigar su secuencia de nucleótidos y otras propiedades. Las técnicas de clonación de genes y aun de genomas completos han avanzado enormemente desde principios del siglo XXI. El tiempo necesario y los costes se han reducido enormemente.

Las tecnologías para clonar células en el laboratorio son incluso más antiguas, siendo practicadas desde mediados del siglo XX. Se utilizan para reproducir un tipo particular de célula, por ejemplo una célula dérmica o hepática, con el fin de investigar sus características. La clonación celular es un proceso natural de dos maneras evidentes. Primero, en el caso de las bacterias y de otros microorganismos que se reproducen mediante clonación; es decir, la escisión de una célula individual en dos células que son más o menos idénticas entre sí y a la célula madre. La clonación celular, o duplicación celular, tiene lugar asimismo en organismos pluricelulares como las plantas o los animales, cuando las células se multiplican mientras forman un tejido concreto, piel, músculo o glóbulos rojos de la sangre. Los organismos multicelulares empiezan como una célula que se duplica una y otra vez, aunque el proceso incluye diferenciación de los tipos celulares que constituyen los diferentes tejidos. En el desarrollo, algunas células se duplican exactamente, o casi exactamente, como es el caso, por ejemplo, de las células dérmicas o de los glóbulos rojos de la sangre, mientras que otras se diferencian durante su replicación. Así, las células madre embrionarias humanas se desarrollan en células epiteliales, células musculares y en los más de 200 tipos de células que existen en los humanos.

La clonación de humanos puede referirse a clonación terapéutica, particularmente la clonación de células embrionarias con el propósito de obtener órganos para su trasplante, o el de obtener células neurales u otras con propósitos medicinales. Mas típicamente la clonación de humanos se refiere a clonación reproductiva, consistente en la transferencia a un óvulo del núcleo de una célula somática para obtener óvulos que pudieran desarrollare en individuos adultos. (En inglés se conoce esta técnica como SCNT: Somatic Cell Nuclear Transfer).

Una técnica de clonación desarrollada recientemente es la MRT (Mitocondrial Replacement Technique o Técnica de Reemplazamiento Mitocondrial), con la que se produce un embrión con genes de tres individuos. Se utiliza cuando la mujer que quiere ser madre lleva en el genoma de sus mitocondrias genes causantes de enfermedades serias. Las mitocondrias del embrión vienen todas de la madre. La técnica consiste en obtener un óvulo de una donante, cuyo núcleo se destruye y se reemplaza con el genoma del núcleo de la mujer que quiere ser madre y con el del padre. El embrión tiene los genes nucleares del padre y de la madre, pero también los genes mitocondriales de la mujer donante.

Un resultado previsto de la investigación sobre clonación de células embrionarias es la clonación de órganos. El "donante" óptimo para una persona que necesita un trasplante de riñón sería un riñón clonado a partir del genoma del paciente. Si las células de una persona se clonan de manera que se diferencien en un riñón, un hígado o algún otro órgano destinado a sustituir un órgano enfermo del donante, el proceso parecería aceptable social y moralmente. Un individuo humano está constituido por alrededor de un billón de células, y un fragmento de piel puede tener millones de células. Teóricamente, se podría extraer material genético de cientos o miles de células de un pequeño fragmento de piel e implantarlo en cada uno de cientos o miles de óvulos genéticamente neutralizados, con lo que se obtendría una multitud de individuos tan parecidos entre sí y con el donante desde el punto de vista genético como lo son dos gemelos idénticos. Ninguna persona en su sano juicio propondría proceder de la manera descrita con un humano, pero el procedimiento podría llevarse a cabo, pongamos por caso, con una vaca productora de grandes cantidades de leche, con lo que se obtendría un rebaño económicamente valioso. De hecho, la clonación de algunos animales domésticos, como vacas y cerdos, se ha llevado a cabo repetidamente por razones comerciales.

En ocasiones se ha sugerido la clonación humana como una manera de mejorar la dotación genética de la especie humana, clonando individuos de grandes logros (por ejemplo, en el deporte, la música, las artes, las ciencias, la literatura o la política) o de virtud reconocida. Aparentemente, dichas sugerencias no se han tomado nunca en serio. Pero algunos individuos han expresado su deseo, por poco realista que sea, de ser clonados, y algunos médicos han difundido alguna vez que estaban dispuestos a realizar la clonación. Los obstáculos e inconvenientes son muchos e insuperables, al menos en el estado actual de conocimientos y de tecnología relevante.

Pero hay una razón fundamental que hace imposible la clonación de un ser humano en sentido estricto. Se trata de la distinción del genotipo o genoma, la constitución genética del individuo, en contraste con su fenotipo, lo que el individuo es. El fenotipo de una persona incluye su morfología, fisiología, comportamiento, 
preferencias, valores morales, preferencias estéticas, creencias religiosas y, en general, todos los rasgos de su cultura adquiridos por imitación, aprendizaje o de cualquier otra manera, y que son parte de la evolución cultural. Está claro que el genotipo influye en lo que el individuo es, pero es algo igualmente claro que no lo determina en un sentido estricto. Las experiencias de un individuo humano a través de toda su vida, conscientes o no, influyen en lo que el individuo resulta ser.

Las influencias del entorno comienzan de manera importante en el seno de la madre y siguen durante la infancia, la adolescencia y la vida entera. Provienen de la familia, los amigos, la escuela, la vida social y política, las lecturas, los estudios, las vivencias estéticas y religiosas, y todo el resto de la experiencia personal. Los biólogos utilizan una abstracción para referirse a aquello que es potencialmente determinado por el genoma de un individuo llamándolo la norma de reacción de ese genoma particular. La denominación norma de reacción se refiere a las posibilidades infinitas de realización del genoma de cada individuo, de las que solo una mínima parte se actualizará de hecho; cuál será la realidad que se actualice, entre los millones de posibilidades, es algo que depende de todas las experiencias del individuo a través de su vida, como acabamos de indicar.

En consecuencia, dos genomas idénticos, concebidos en senos de madres diferentes, no dan lugar en absoluto a individuos idénticos. El genotipo de una persona tiene un número ilimitado, prácticamente infinito, de experiencias posibles, de las cuales solo algunas serán experimentadas durante la vida de un individuo concreto. Necesariamente, las experiencias de la vida cambian siempre de una persona a otra, incluso en el caso de gemelos idénticos, pero sería mucho mayor en el caso de clonar el genoma de un humano adulto. Las circunstancias dispares de la vida, experimentadas una generación más tarde y en entornos drásticamente diferentes, tendrían ciertamente como resultado un individuo muy diferente, aunque anatómicamente se pareciera al donante del genoma en una edad parecida.

En la segunda mitad del siglo XX, a medida que se producían progresos espectaculares en genética, así como en la ingeniería genética, se plantearon algunas propuestas utópicas, al menos como ideas que había que explorar y considerar como posibilidades una vez que las tecnologías hubieran avanzado lo suficiente. Como acabamos de ver, dichas propuestas sugerían que se clonaran personas de grandes logros intelectuales o artísticos, o de gran virtud. Si esto se conse- guía en gran número, se aducía, la constitución genética de la humanidad mejoraría considerablemente.

Si esto se hiciera, que no se hará, los utópicos dispuestos a clonar individuos excelsos por su carácter, inteligencia y otras cualidades deseables, se llevarían una sorpresa. No hay razón alguna para esperar que los genomas de individuos con atributos excelentes vayan a producir a su vez individuos con unos atributos semejantes. Como se ha afirmado, el genoma determina solo la norma de reacción del individuo. Pero, en ambientes distintos, un mismo genoma da lugar a individuos muy dispares. Es imposible proveer al genotipo de una persona eminente con el mismo ambiente, en todos sus detalles, en el que vivió la persona eminente de la que proviene el genotipo: los mismos estímulos y experiencias que la persona tuvo, incluyendo de manera importante sus padres y otros individuos con los que interaccionó a través de toda su vida. Tal cosa es, evidentemente, imposible. Pero incluso si fuese viable, los resultados variarían sin duda a causa de la presencia de fenómenos no lineales en la cadena compleja que lleva desde los genes a la persona.

George W. Beadle, eminente genetista y premio Nobel, escribió hace varias décadas:

\footnotetext{
"Pocos de entre nosotros hubiéramos defendido la multiplicación diferencial de los genes de Hitler. Pero ¿quién puede decir que en un contexto cultural distinto Hitler no hubiera podido ser uno de los grandes líderes de la humanidad, o Einstein no hubiera podido ser un político malvado?" (Ayala, 2015).
}

Pretendiendo clonar un Einstein, un Lincoln y al Papa Francisco, podríamos obtener en cambio un Stalin, un Hitler y un Bin Laden. Clonar los genes que una persona recibió en el momento de la concepción de su padre y su madre podría producir una persona que podría parecerse a la primera en el aspecto físico, pero que con toda seguridad sería muy diferente con respecto a lo que más cuenta, lo que se incluye en términos tales como "personalidad", "carácter" o afines.

De nuevo, la constitución genética de una persona puede clonarse; el individuo, no. Un individuo es el resultado de las interacciones entre el genotipo de dicho individuo y el ambiente. La constitución genética de una persona está fijada en la concepción, formada por los dos conjuntos de genes recibidos, uno del padre y el otro de la madre. El ambiente incluye todas las experiencias a las que dicho genotipo ha estado expuesto desde la concepción hasta la muerte, desde el seno de la madre y a través de la infancia, la escolarización, la familia y la sociedad. 
¿Es posible que se den circunstancias capaces de justificar el que un individuo se reproduzca por clonación (una vez que la tecnología apropiada haya avanzado lo suficiente)? Se han citado, por ejemplo, el deseo de un matrimonio estéril, o de un hombre o una mujer que no quieren casarse, entre otras circunstancias más especiales. No es mi propósito realizar un juicio detallado sobre este asunto, aunque mi opinión es definitivamente negativa al respecto. En cualquier caso, hay cada vez más países que han declarado ilegal la clonación reproductiva humana, es decir, el proyecto de obtener un humano clonado a partir del genoma de otro ser humano.

El progreso de las ciencias biológicas ha dotado a la humanidad actual de la cirugía genética entre otras herramientas capaces de modificar el genoma. Otras técnicas aún más eficaces aparecerán con toda probabilidad en un futuro próximo. Es preciso tomar decisiones, y para tomarlas correctamente necesitamos toda la prudencia y todos los conocimientos que puedan ser reunidos: el bienestar futuro e incluso la supervivencia de la humanidad están en juego. Los biólogos, médicos, psicólogos, sociólogos, abogados, filósofos, teólogos, líderes políticos y religiosos deben prestar atención a las posibilidades que la biología moderna ha abierto para modificar y controlar el genoma humano. Los beneficios posibles son muchos; las catástrofes imaginables, también. Por decirlo de forma figurativa, el reino de la luz y el reino de las tinieblas están en el horizonte de la humanidad; es preciso asegurarse de que, tratando de llegar a la ciudad de Utopía, no tomamos el camino hacia la autodestrucción y el infierno. ${ }^{2}$

\section{NOTAS}

1. La acondroplasia es un tipo de enanismo causado por un gen dominante que causa que sus portadores tengan torso normal, pero brazos y piernas cortos y frente protuberante. Velázquez perpetuó en sus cuadros a varios acondroplásticos, como el bufón Sebastián de Morra y Mari Bárbola que aparece en Las Meninas en la esquina inferior derecha, detrás del perro y junto a quien parece un niño, aunque se trata también de un enano, si bien de tipo diferente.

2. En el año 2004, la cuestión de clonar humanos fue considerada por los parlamentos de varios países que estaban también explorando si la investigación con células troncales debería ser apoyada o al menos permitida. El 12 de marzo de 2004, el Parlamento de Canadá (Canadian Parliament) aprobó algunas leyes que permitían la investigación con células troncales bajo ciertas condiciones, pero la clonación de humanos fue prohibida, como también fue prohibida la venta de esperma o el pago a donantes de óvulos o a madres sustitutas. El Parlamento francés (French Parliament) adoptó el 9 de julio de 2004 una nue-

\section{BIBLIOGRAFÍA}

Ayala, F. J. (2015). Cloning humans? Biological, ethical, and social considerations. Proceedings of the National Academy of Sciences, 112 (29), pp. 8879-8886. https://doi.org/10.1073/ pnas. 1501798112

Baltimore, D., Berg, P. y Botchan, M. (2015). A prudent path forward for genomic va ley de bioética que permitió la investigación con células troncales, pero que califica la clonación de una persona como "un crimen contra la especie humana". Experimentos de clonación reproductora serían penalizados hasta con 20 años de cárcel. En Japón el Gabinete del Consejo de Ciencia y Tecnología (Cabinet Council for Science and Technology Policy) votó el 23 de julio de 2004 aceptar recomendaciones que permitieran clonar embriones humanos para la investigación científica, pero no clonar individuos. El 14 de enero de 2001, el gobierno británico enmendó la ley de 1990 sobre fertilización y embriología humanas (Human Fertilization and Embryology Act), permitiendo la investigación con células troncales y la clonación terapéutica. La ley de 2008 sobre fertilización y embriología humana prohíbe explícitamente la clonación reproductora, pero permite la experimentación con células troncales para el tratamiento de la diabetes y de las enfermedades de Parkinson y Alzheimer. El 3 de febrero de 2014, la Casa de los Comunes (House of Commons) votó legalizar la técnica de la terapia genéti-

engineering and germline gene modification. Science, 348 (6230), pp. 3638. https://doi.org/10.1126/science. aab1028

Callaway, E. (2016). Embryo editing gets the green light. Nature, 530, pp. 18 36. https://doi.org/10.1038/nature.2016.19270 ca de reemplazamiento mitocondrial, o fertilización in vitro con tres personas, con la cual las mitocondrias del óvulo de una donante contribuyen al embrión de una pareja (la técnica llamada MRT, Mitochondrial Replacement Technique). Más recientemente, el 1 de febrero de 2016, la Human Fertilization and Embryology Authority (Autoridad sobre la fertilización y la embriología humana) británica ha aprobado la posibilidad de clonar genéticamente embriones humanos con propósitos experimentales. Pero los experimentos deben terminar después de siete días con la destrucción de los embriones (Callaway, 2016). En los Estados Unidos no hay actualmente leyes federales que prohíban absolutamente la clonación. Pero en trece estados (Arkansas, California, Connecticut, lowa, Indiana, Maryland, Massachusetts, Michigan, New Jersey, North Dakota, Rhode Island, South Dakota y Virginia) está prohibida la clonación reproductora, y en tres estados (Arizona, Maryland y Missouri) está prohibido usar fondos del gobierno estatal para la investigación sobre clonación reproductora (Ayala, 2015).

Crow, J. F. (1958). Some possibilities for measuring selection intensities in man. Human Biology, 30 (1), pp. 1-13.

Dobzhansky, Th. (1973). Genetic Diversity and Human Equality. New York: Basic Books.

Doudna, J. A. y Charpentier, E. (2014). The new frontier of genome engineer- 
ing with CRISPR-Cas9. Science, 346 (6213), pp. 1077-1086. https://doi. org/10.1126/science.1258096

Ledford, H. (2015). CRISPR, the disruptor. Nature, 522, pp. 20-24. https://doi. org/10.1038/522020a

Morange, M. (2015). What history tells us XXXIX. CRISPR-Cas: From a prokary- otic immune system to a universal genome editing tool. Journal of Biosciences, 40 (5), pp. 829-832. https://doi. org/10.1007/s12038-015-9575-8

Slaymaker, I. M., Gao, L. y Zetsche, B. (2016). Rationally engineered Cas9 nucleases with improved specificity. Science, 351 (6268), pp. 84-86. https://doi. org/10.1126/science.aad5227
Zimmerman, C. (2015, 15 octubre). Editing of Pig NDA May Lead to More Organs for People. The New York Times. [En línea]. Disponible en http://www.nytimes.com/2015/10/20/science/editingof-pig-dna-may-lead-to-more-organsfor-people.html 